

\section{Relações Públicas somente para grandes empresas?}

Carolina de Avellar Barbosa

- Especialista em Gestão Estratégica em Comunicação Organizacional e Relações Públicas (Gestcorp) pela Escola de Comunicações e Artes da Universidade de São Paulo (ECA-USP)

- Bacharel em Relações Públicas e em Jornalismo pela Faculdade de Comunicação e Artes da Pontifícia Universidade Católica de Minas Gerais (PUC-MG)

- Gerente de comunicação da CL-A Comunicações

- carolina.avellar@uol.com.br 


\section{Resumo}

Este artigo constitui uma reflexão a respeito da importância do planejamento de Relações Públicas para organizações de micro ou pequeno porte. As variáveis e diferenças entre grandes e pequenas empresas que podem determinar ações de comunicação e como é possível traçar o planejamento a partir da identificação dos públicos estratégicos dessas organizações também são objeto de discussão no texto.

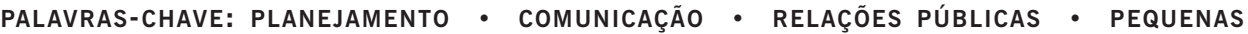
EMPRESAS - PROFISSIONAIS LIBERAIS

\section{Abstract}

This article is a reflection on the importance of Public Relations planning for "micro" (equivalent to U.S. Subchapter 5) or small organizations. Dealing with the variables and differences between large and small organizations that could determine communication actions or how it should be possible to outline the planning, using identification of the strategic publics, are also subject-matter for discussion in the text.

KEYWORDS: PLANNING - COMMUNICATION • PUBLIC RELATIONS • SMALL ORGANIZATIONS - LIBERAL PROFESSIONALS

\section{Resumen}

Este artigo constituye una reflexión sobre la importancia de la planificación de Relaciones Públicas para organizaciones de micro o pequeño porte. Se habla también sobre las variantes y diferencias entre grandes y pequeñas empresas que pueden determinar acciones de comunicación y sobre cómo es posible pensar la planificación partiendo de la identificación de los públicos estratégicos.

PALABRAS CLAVE: PLANIFICACIÓN • COMUNICACIÓN • RELACIONES PÚBLICAS - PEQUEÑAS EMPRESAS • PROFESIONALES LIBERALES 
A s pequenas empresas estão se aproximando, aos poucos, das grandes organizações no Brasil, seja em importância, em quantidade, em expectativa de cresimento ou em criação de renda e emprego. Os sinais dessa mudança estão por todos os lados e podem ser observados em pesquisas e indicadores sociais, na economia ou no dia-a-dia do trabalho. A manchete de capa da Gazeta Mercantil de $1^{\circ}$ de fevereiro de 2007 comprova: segundo pesquisa realizada pela Confederação Nacional da Indústria $(\mathrm{CNI})$, pequenas e médias empresas alavancam a indústria. Foram elas as principais responsáveis pelo crescimento da produção industrial no quarto trimestre de 2006. Essa foi a primeira vez, desde 1998, quando a CNI começou a realizar a Sondagem Industrial, que as grandes empresas não ficaram na frente. Historicamente, elas impulsionam a expansão do setor.

Os números mostram mais (quadro 1). De acordo com a pesquisa apresentada pelo Serviço Brasileiro de Apoio às Micro e Pequenas Empresas (Sebrae), em novembro de 2006, a quantidade de micro e pequenas empresas (MPEs) no Brasil aumentou 22,1\%, entre 2000 e 2004, enquanto as grandes empresas registraram taxa de expansão de 19,5\%. Dos 924 mil novos estabelecimentos abertos no Brasil nesse período, 99\% eram micro e pequenas empresas. O indicador de evolução das micro/pequenas foi de 53,2 pontos, enquanto o das médias/grandes ficou em 52 pontos.

\section{Quadro 1. Dados comparativos entre micro/pequenas e médias/grandes empresas}

\begin{tabular}{|l|c|c|}
\hline Itens & Micro/Pequenas & Médias/Grandes \\
\hline Indicador de evolução & 53,2 pontos & 52 pontos \\
Taxa de expansão (2000-2004) & $22,1 \%$ & $19,5 \%$ \\
\hline Total de estabelecimentos (2004) & 5,05 milhões & 81,9 mil \\
\hline Representatividade de organizações & $98 \%$ & $2 \%$ \\
\hline Representatividade no PIB & $20 \%$ & $80 \%$ \\
\hline Crescimento nos postos de trabalho (1995-2000) & $25,9 \%$ & $0,3 \%$ \\
\hline Expectativa de contratações (janeiro de 2007) & $55 \%$ & $49,6 \%$ \\
\hline
\end{tabular}

Fontes: Observatório das MPEs (Sebrae-SP), Sondagem Industrial (CNI) 
Esse movimento de mudança no ambiente empresarial teve início no Brasil na década de 1980, quando as empresas tiveram de se ajustar às crises econômicas, aos avanços tecnológicos e ao acirramento da concorrência trazido pela globalização (KON, 2001 , p. 7). Hoje, os números demonstram que realmente existe uma nova organização do trabalho. Dados recentes do Instituto Brasileiro de Geografia e Estatística (IBGE) mostram que, no Brasil, existem 4,6 milhões de empresas e os pequenos negócios (formais e informais) respondem por mais de dois terços das ocupações do setor privado.

Vieira e Clemente (2006) comparam informações do IBGE, do Ministério do Trabalho, do Sebrae, da Associação Brasileira de Franchising (ABF), do Instituto de Pesquisa Econômica Aplicada (Ipea) e do Global Entrepreneurship Monitor (GEM) nos dez últimos anos, e constatam que o número de postos de trabalho nas empresas com mais de mil funcionários caiu $41 \%$. Já nas empresas com até quatro empregados, houve aumento de 150\% nas vagas. Enquanto, em 1990, as grandes empresas empregavam 4,4 milhões de pessoas, as pequenas registravam 1,5 milhão. Já em 2003, esse número caiu para 2,6 milhões nas grandes empresas, e subiu para 3,8 milhões nas pequenas. Nassif (2006) agrega informações ainda mais precisas ao registrar que, segundo estudos do Sebrae nacional, de 1995 a 2000, o número de postos de trabalho cresceu $0,3 \%$ nas empresas de grande porte e $25,9 \%$ nas micro empresas.

\section{O planejamento de Relações Públicas deve acompanhar as mudanças nas empresas}

Os dados apresentados mostram que há uma espécie de migração do trabalho em massa para o trabalho especializado, segmentado e diferenciado no Brasil. O mundo mudou, o trabalho mudou e as necessidades das empresas são outras. Toda a parafernália tecnológica dos novos tempos reduziu a necessidade de trabalho físico e presencial. Hoje, qualquer pessoa que tenha um computador conectado à Internet pode ser um empresário, um empreendedor, e realizar, sozinho, tarefas que, há dez anos, demandariam uma equipe e uma estrutura formal para serem feitas. Os negócios acontecem em rede e o acesso à informação é ilimitado. A terceirização de parte das atividades das empresas já se apresenta como uma nova modalidade de trabalho e tem levado à difusão de empreendimentos menores e à ampliação do número de profissionais autônomos e liberais.

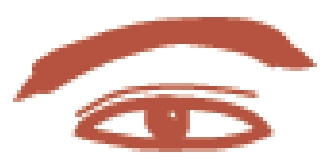


Muitos deles são profissionais flexíveis, ágeis e dinâmicos, proprietários de empresas de micro e pequeno porte (quadro 2), desempenhando-se como terceirizados ou prestadores de serviços para os mais diversos segmentos, participando de licitações do setor público para construção de edifícios, estradas e reformas de prédios, atuando no agronegócio, no comércio, na área da saúde, em clínicas, laboratórios e hospitais, realizando consultorias para entidades e vendendo ou exportando seus serviços como se fossem simples produtos.

$\mathrm{Na}$ verdade, eles se tornaram produtos, mas produtos bem-sucedidos do século XXI. Por isso, é cada vez maior o número de profissionais que se desvinculam de grandes empresas e passam a prestar serviços como consultores e que, ainda assim, continuam precisando se comunicar com seus públicos de relacionamento. O perfil das empresas que estão à frente da economia está mudando e elas passam a ter demandas diferenciadas também de comunicação e planejamento. É aí que podem surgir novas formas de ação para os conhecidos planos de Relações Públicas e também oportunidades de atuação para os profissionais da área.

\section{Quadro 2. Perfil das micro e pequenas empresas na economia}

\begin{tabular}{|l|}
\hline 0 que as micro e pequenas empresas representam \\
\hline $98 \%$ das empresas do País \\
\hline $67 \%$ das pessoas ocupadas $\left(^{*}\right.$ ) \\
\hline $20 \%$ do PIB nacional \\
\hline $56 \%$ dos empregados com carteira assinada (CLT) \\
\hline $62 \%$ das empresas exportadoras \\
\hline $2,3 \%$ do valor das exportações \\
\hline $\begin{array}{l}\text { (*) Pessoas ocupadas no setor privado. Inclui todos os tipos de ocupações: sócios-proprietários, } \\
\text { familiares e empregados com e sem carteira. }\end{array}$ \\
Fonte: Observatório das MPEs - novembro de 2006 (Sebrae-SP).
\end{tabular}

No dia-a-dia das empresas, seja de pequeno, médio ou grande porte, não se trata mais apenas de produzir com qualidade e ter um preço acessível ou um serviço relevante. Para o empregado, não se trata mais de sobreviver trabalhando dignamente para contar com o salário no final do mês. Tachizawa e Rezende (2000) afirmam que o novo ambiente empresarial exige posturas diferenciadas quanto à qualidade, à rapidez de capacidade de resposta e tomada de decisão, à tecnologia, ao senso de responsabilidade social e ambiental, à cooperação entre organizações concorrentes, ao regime de 
leis e direito do trabalho, impactando fortemente na flexibilidade dos processos, dos mercados, dos produtos e padrões de consumo.

E, então, como as micro e pequenas empresas, frente a tantos desafios, podem expandir sua atuação, se diferenciar, favorecer a oferta de seus serviços e atender às crescentes expectativas de seus clientes ou da comunidade onde atuam? Será que podem prescindir do apoio de ferramentas de comunicação? Ou, ainda, como podem obter bons resultados a partir do relacionamento com fornecedores, parceiros, associações, concorrentes, se não possuem sequer departamentos estruturados como os das grandes organizações?

Em pesquisa realizada como base para a monografia de conclusão de curso de pósgraduação lato sensu $\mathcal{1}^{1}$, dedicamos-nos a refletir sobre essas questões e a sugerir planos de Relações Públicas que possam ser aplicados em empresas de pequeno porte, comandadas por profissionais liberais. Foram realizadas entrevistas em profundidade com três profissionais liberais, que atuam por conta própria, caracterizados como micro ou pequenos empreendedores, em ramos diferenciados de atividade - arquitetura, odontologia e advocacia. Nesse artigo, tomaremos como exemplo o planejamento proposto para a profissional de arquitetura.

A partir da pesquisa, foi possível identificar as necessidades e as expectativas de comunicação de cada um dos profissionais, elaborar uma análise do perfil e das demandas específicas dessas organizações de micro ou pequeno porte e, posteriormente, um planejamento de ações de Relações Públicas para cada um deles, identificando e classificando suas relações com fornecedores, parceiros e clientes, definindo objetivos, estratégias e planos de ações (quadros 5 a 10).

É fato que os profissionais de Relações Públicas têm sido, historicamente, direcionados para atuar em grandes corporações, organizações já reconhecidas pela sociedade ou mesmo em médias indústrias ou empresas prestadoras de serviço. E o foco dessa atuação esteve constantemente presente nas discussões sobre valorização da profissão e necessidade de reconhecimento da diretoria das empresas, dos altos executivos responsáveis pelas decisões corporativas. Por que não, agora, acompanhar as mudanças de cenários internos e externos das organizações e propor uma forma de atuação diferenciada para a atividade de Relações Públicas?

1 BARBOSA, Carolina de Avellar. Planejamento de Relações Públicas aplicado para profissionais que trabalham por conta própria e para profissionais liberais. $161 \mathrm{f}$. Monografia (Especialização em Relações Públicas) - Escola de Comunicações e Artes. São Paulo: Universidade de São Paulo, 2006. 
RELAÇÕES PÚBLICAS SOMENTE PARA GRANDES EMPRESAS? • CAROLINA DE AVELLAR BARBOSA

\section{Planejamento de Relações Públicas para micro e pequenas empresas}

Frente às mudanças que geraram um novo perfil de empresas e trabalho, a comunicação assume um papel vital como recurso estratégico de entendimento, persuasão e negócios, cabendo ao profissional de Relações Públicas traçar e executar essa estratégia comunicacional para essa "nova empresa". Por isso, ele deve atuar como um intermediador, um administrador dos relacionamentos institucionais e de negócios da empresa, "segundo princípios operacionais, mercadológicos e éticos de aplicação global e adequados ao contexto socioeconômico de cada situação e ao contexto de atuação de cada organização” (FRANÇA, 1997, p. 8).

Sabemos que as organizações, independentemente de seu porte ou de sua natureza, são influenciadas pelo ambiente em que estão inseridas. Por isso, a prática do planejamento é indiferente a empresas públicas, privadas, de grande ou pequeno porte, já que todas estão em ambientes sociais essencialmente mutantes. Ao contrário do que pode parecer ao senso comum, o planejamento não é uma forma de engessar o negócio e delimitar futuras decisões. É, sim, uma ferramenta que permite interferir e transformar o curso das decisões presentes, com vistas para o futuro almejado, já que está sempre vinculado à realidade da vida das pessoas, dos grupos e das diversas organizações e instituições (KUNSCH, 2003, p. 204).

Desta forma, o planejamento pode também ser tratado como ferramenta para apoiar a ação de micro e pequenas empresas, considerando seus contextos, seus ambientes específicos, suas dificuldades e realidades. Sendo grandes líderes ou não, os profissionais à frente dessas empresas precisam saber planejar suas ações e delinear estratégias. Por isso, a atuação de Relações Públicas vem somar esforços junto a esses empreendedores. As micro e pequenas empresas podem não necessitar de procedimentos complicados nem de técnicas sofisticadas de administração, mas não podem prescindir de alguns elementos básicos, como objetivos, diagnóstico, análise e, principalmente, planejamento. Com o apoio das Relações Públicas é possível pensar, gerir e administrar estrategicamente, realizando ações coerentes com as necessidades e expectativas da organização, independentemente do seu porte.

É importante mencionar que as micro e pequenas empresas e, principalmente, os profissionais que as comandam, possuem características peculiares que podem determinar também a atuação das Relações Públicas (quadro 3). Por definição, em negócios de pequeno porte, os profissionais contam especialmente com recursos próprios e quase sempre escassos e, na maioria das vezes, possuem pouco ou nenhum conhecimento de gestão ou mesmo de questões financeiras. São micro e pequenos empresários que, muitas vezes, não dominam conceitos básicos de planejamento, vendas, marketing ou projeções de faturamento e, ainda assim, precisam lidar com uma gama de dificuldades, sem poder prescindir de atender bem o cliente, prospectar novos serviços e mercados e manter a atenção em boas oportunidades. 


\section{Quadro 3. Algumas comparações entre pequena e grande empresa que podem determinar o planejamento de Relações Públicas}

\begin{tabular}{|c|c|c|}
\hline & Grande empresa & Pequena empresa \\
\hline Papel do administrador & $\begin{array}{l}\text { Papéis bem definidos, de acordo } \\
\text { com posição na organização. }\end{array}$ & $\begin{array}{l}\text { Definições de papéis são mais } \\
\text { amplas e, às vezes, até ambíguas. }\end{array}$ \\
\hline Atuação do administrador & $\begin{array}{l}\text { Descentralizada e distribuída de } \\
\text { acordo com funções e tarefas. }\end{array}$ & $\begin{array}{l}\text { Centralizada. Proprietário age em } \\
\text { diversas frentes, sendo, ao mesmo } \\
\text { tempo, representante, negociador } \\
\text { operador e empreendedor. }\end{array}$ \\
\hline Estrutura & $\begin{array}{l}\text { Menos flexível, mais burocrática, } \\
\text { baseada em processos gerenciais } \\
\text { e sistemas rígidos. }\end{array}$ & $\begin{array}{l}\text { Mais enxuta, competitiva, carente } \\
\text { de apoio direto. Faltam } \\
\text { informações e capacidade gerencial. }\end{array}$ \\
\hline Motivação & Promoções, salários e status. & $\begin{array}{l}\text { Ganhos percebidos com } \\
\text { independência, novidades } \\
\text { e automotivação. }\end{array}$ \\
\hline Hierarquia & $\begin{array}{l}\text { Atividades são delegadas e } \\
\text { supervisionadas. A hierarquia } \\
\text { é a base do relacionamento diário } \\
\text { entre funcionários e superiores. }\end{array}$ & $\begin{array}{l}\text { Envolvimento direto com tarefas } \\
\text { e serviço voltado para si próprio } \\
\text { e para os clientes, apenas. }\end{array}$ \\
\hline Respostas e resultados & $\begin{array}{l}\text { Dependendo da estrutura, busca } \\
\text { criar processos e programas para } \\
\text { melhorar resultados. }\end{array}$ & $\begin{array}{l}\text { Adapta-se com mais facilidade } \\
\text { e rapidez às novas situações } \\
\text { de mercado. }\end{array}$ \\
\hline Cliente & $\begin{array}{l}\text { Quer estar cada vez mais próxima } \\
\text { do cliente, apesar de toda } \\
\text { a estrutura e todo o processo } \\
\text { elaborado para mantê-la. }\end{array}$ & $\begin{array}{l}\text { Por estar naturalmente mais próxima } \\
\text { do cliente, consegue perceber } \\
\text { necessidades e detectar oportunidades } \\
\text { exatamente quando surgem. }\end{array}$ \\
\hline Relacionamento & $\begin{array}{l}\text { Pode ser previsivel e } \\
\text { institucionalizado em fluxos } \\
\text { determinados pela empresa. }\end{array}$ & $\begin{array}{l}\text { Envolve todo o negócio, } \\
\text { determinando acordos, contratos, } \\
\text { indicações e, conseqüentemente, } \\
\text { a fidelização e a sobrevivência } \\
\text { no mercado. }\end{array}$ \\
\hline Reputação & $\begin{array}{l}\text { Determina relação com } \\
\text { investidores, clientes, } \\
\text { fornecedores, parceiros, } \\
\text { mas não compromete } \\
\text { sua atuação. }\end{array}$ & $\begin{array}{l}\text { Está muito atrelada à imagem. } \\
0 \text { custo de uma jogada errada } \\
\text { torna-se cada vez mais punitivo; } \\
\text { boca-a-boca e indicações são } \\
\text { determinantes para zelar pela boa } \\
\text { reputação. Vai além da imagem. }\end{array}$ \\
\hline Comunicação & $\begin{array}{l}\text { Planejamento e importância } \\
\text { reconhecidos, principalmente para } \\
\text { lidar com crises e/ou em situações } \\
\text { complicadas. Potenciais explorados } \\
\text { em decisões superiores. }\end{array}$ & $\begin{array}{l}\text { Precária, amadora; aplicações } \\
\text { imediatistas; ausência de tempo e, } \\
\text { às vezes, de recursos para realizar } \\
\text { ações. Desconhecimento do } \\
\text { potencial de comunicação. }\end{array}$ \\
\hline Expressões constantes & $\begin{array}{l}\text { Resultados, estratégia, } \\
\text { planejamento, lucros. }\end{array}$ & $\begin{array}{l}\text { Credibilidade, confiança, } \\
\text { fidelidade, prospecção. }\end{array}$ \\
\hline
\end{tabular}

Fontes: Cavalcanti (1981), Mintzberg (1973), Pinheiro (1996), Albrecht (2002), Tavares (1991), Almeida (1994). 
As diferenças são claramente perceptíveis, principalmente quando comparamos as oportunidades vislumbradas pelos empresários de um grande negócio com as de empresários de um pequeno negócio. Geralmente, esses últimos entendem a importância do planejamento, mas têm dificuldades de aplicá-lo, de definir prioridades, de enumerar objetivos e ações. Desta forma, planejar estrategicamente seu relacionamento com públicos de interesse e introduzir conceitos e aplicações de Relações Públicas em um negócio comandado por profissionais autônomos não deixa de ser tão relevante.

\section{Ponto de partida para o planejamento: análise dos públicos de relacionamento}

O objetivo das organizações diante de seus públicos tornou-se extremamente específico, visando ao desenvolvimento de parcerias comerciais de interesse para todas as partes. Ao se pensar em empresas de micro e pequeno porte, comandadas por profissionais autônomos ou liberais, não é diferente. Por isso, a necessidade de interação com o ambiente interno e externo também influencia essas empresas, ainda que em menor grau e com relações simplificadas. As demandas por uma análise de oportunidades e riscos inerentes à sua atuação existem nos mesmos moldes das grandes corporações.

O valor das Relações Públicas como função estratégica está exatamente em equilibrar os interesses da sociedade com os interesses dos clientes com os quais os profissionais trabalham. "Entendemos que a ação de Relações Públicas é um diálogo e que o propósito é administrar o conflito e construir, manter e engrandecer os relacionamentos”, escreve Ferrari (2003, p. 12-13), concluindo: “Dessa maneira, as Relações Públicas atuam para construir relacionamentos com seus públicos estratégicos”.

A busca por uma avaliação dos públicos que se relacionam com as organizações é de extrema importância, principalmente porque "as Relações Públicas são mais eficazes quando o profissional identifica os públicos estratégicos e desenvolve uma rede de relacionamentos que permite que ambas as partes possam ser beneficiadas" (FERRARI, 2003, p. 8). Assim, a análise dos públicos com que a empresa se relaciona também deve ser o ponto de partida para o desenvolvimento de um planejamento de Relações Públicas para micro e pequenos empreendimentos.

É preciso conhecer detalhes desses fluxos, já que os critérios de definição de públicos interno, externo e misto não satisfazem mais as condições atuais de relacionamento das organizações com seus públicos de interesse. Para tanto, buscamos um novo critério que possa defini-los adequadamente. Esse critério, além de precisar o tipo e a extensão de relacionamento, também considera a "dimensão de seu peso, na sua constituição, na sua sobrevivência, nos aspectos de sua interdependência e dos objetivos de relacionamentos, permanentes ou eventuais", conforme preconiza França (2003, p. 21). 
Além de identificar, analisar e classificar os públicos de relacionamento da pequena organização, propomos algumas etapas que podem facilitar o desenvolvimento de um planejamento de Relações Públicas para micro e pequenas empresas, como mostra o quadro 4.

\section{Quadro 4. Roteiro para planejamento de Relações Públicas adaptado para micro e pequenas empresas}

1. Realização de entrevista em profundidade para gerar fonte de informações

2. Identificação, análise e classificação dos públicos de relacionamento

3. Diagnóstico (partindo de avaliação dos pontos fortes e fracos, oportunidades e ameaças da empresa)

4. Definição de prazos e objetivos para o plano de Relações Públicas

5. Determinação de estratégias sobre como atingir os objetivos

6. Proposição de programas e projetos de ação a serem implantados

7. Determinação de prioridades e recursos necessários

8. Definição de cronograma e estimativa de custos

9. Estabelecimento de critérios de avaliação e controle de resultados

Fontes: Kunsch (2003), Tavares (1991) e Oliveira (1999).

Seguindo esses passos, à luz de roteiros aplicados em planejamento de Relações Públicas de grandes corporações, é possível levar às micro e pequenas empresas as técnicas e teorias de forma adaptada e exeqüível.

\section{Exemplo de planejamento de Relações Públicas em micro}

e pequenas empresas

O profissional que comanda uma micro ou pequena empresa necessita de uma comunicação diferenciada, segmentada e específica. São, em alguns momentos, demandas por ações de comunicação similares àquelas de grandes empresas, como, por exemplo, quando se trata de prospectar e conquistar clientes e receita. Mas, ao mesmo tempo, são necessidades diferentes das de grandes empresas, principalmente porque precisam ser pessoais, íntimas e confidentes, mas também comerciais e financeiramente interessantes para um único profissional e não para uma rede de acionistas ou diretores. 
O planejamento de Relações Públicas pode ser uma saída para lidar com as variáveis da realidade dessas organizações e, assim, facilitar o contato desse profissional com seu ambiente de atuação. Observamos que o papel das Relações Públicas está mais voltado para o apoio e a orientação de ações e tarefas, fornecendo subsídios para que micro e pequenas empresas atuem livremente. Assim, conhecer os públicos mais importantes com que elas se relacionam e planejar atividades específicas para cada um deles pode ser uma forma de alcançar a diferenciação e o sucesso.

Como exemplo, demonstrado no quadro 5 , podemos arrolar os públicos mencionados por um profissional de arquitetura, que fazem parte de seus contatos diários. Eles foram hierarquizados e classificados de acordo com critérios de relacionamento, expectativas da empresa, grau de interação e de interdependência entre as partes, sua importância, seus objetivos e suas prioridades. Para elaboração desta classificação de públicos, foi utilizada como base a tipologia proposta por França (2004).

\section{Quadro 5. Classificação de públicos para profissional de arquitetura, identificados e hierarquizados a partir de entrevista em profundidade}

\begin{tabular}{|c|c|c|c|c|}
\hline Públicos & Relação & $\begin{array}{l}\text { Tipo de público } \\
\text { (nível de dependência) }\end{array}$ & $\begin{array}{l}\text { Grau de } \\
\text { envolvimento }\end{array}$ & $\begin{array}{l}\text { Objetivo da } \\
\text { relação }\end{array}$ \\
\hline Clientes & - Negocial & $\begin{array}{l}\text { - Essencial } \\
\text { - Não-constitutivo }\end{array}$ & $\begin{array}{l}\text { - Prioritário } \\
\text { - Total }\end{array}$ & - Gerar receita \\
\hline $\begin{array}{l}\text { Futuros } \\
\text { clientes }\end{array}$ & $\begin{array}{l}\text { - Negocial } \\
\text { - Social }\end{array}$ & $\begin{array}{l}\text { - Não-essencial } \\
\text { - Não-constitutivo }\end{array}$ & $\begin{array}{l}\text { - Prioritário } \\
\text { - Freqüente }\end{array}$ & - Gerar negócios \\
\hline Fornecedores & $\begin{array}{l}\text { - De parceria } \\
\text { - Operacional }\end{array}$ & $\begin{array}{l}\text { - Essencial } \\
\text { - Não-constitutivo } \\
\text { - Primário }\end{array}$ & $\begin{array}{l}\text { - Prioritário } \\
\text { - Permanente }\end{array}$ & $\begin{array}{l}\text { - Oferecer bons } \\
\text { serviços }\end{array}$ \\
\hline Parceiros & - De parceria & $\begin{array}{l}\text { - Não-essencial } \\
\text { - Não-constitutivo }\end{array}$ & - Parcial & $\begin{array}{l}\text { - Indicar e apoiar } \\
\text { decisões }\end{array}$ \\
\hline Imprensa & $\begin{array}{l}\text { - Social } \\
\text { - Política }\end{array}$ & $\begin{array}{l}\text { - Não-essencial } \\
\text { - De rede de } \\
\text { interferência }\end{array}$ & $\begin{array}{l}\text { - Parcial } \\
\text { - Ocasional }\end{array}$ & - Divulgar ações \\
\hline Concorrentes & - Social & • Não-essencial & $\begin{array}{l}\text { - Parcial } \\
\text { - Indiferente }\end{array}$ & $\begin{array}{l}\text { - Manter } \\
\text { referência }\end{array}$ \\
\hline Crea* & $\begin{array}{l}\text { - Política } \\
\text { - Classista }\end{array}$ & $\begin{array}{l}\text { - Não-essencial } \\
\text { - Setorial associativo }\end{array}$ & $\begin{array}{l}\text { - Parcial } \\
\text { - Indiferente }\end{array}$ & $\begin{array}{l}\text { - Regular } \\
\text { e controlar }\end{array}$ \\
\hline Governo & - Política & $\begin{array}{l}\text { - Não-essencial } \\
\text { - Setorial comunitário }\end{array}$ & $\begin{array}{l}\text { - Parcial } \\
\text { - Indiferente }\end{array}$ & - Prover leis \\
\hline
\end{tabular}

${ }^{*}$ Conselho Regional de Engenharia, Arquitetura e Agronomia.

Fonte: Barbosa (2006, p. 99). 
Essa identificação é complexa, pois a determinação dos públicos é flexível, situacional e não fixa, diferindo de empresa para empresa, de acordo com seus objetivos. Mas também, por esse motivo, consideramos que este modelo pode ser aplicado ao planejamento de Relações Públicas para organizações com perfis muito particulares e objetivos de atuação totalmente diferenciados, exatamente como é o caso das micro e pequenas empresas. No caso aqui apresentado, por exemplo, o profissional de arquitetura possui relações muito peculiares e dinâmicas com clientes, fornecedores, parceiros, concorrentes e futuros clientes.

Por isso, a classificação e o entendimento dos públicos com os quais esse profissional se relaciona é fundamental para o direcionamento preciso das atividades a serem sugeridas no planejamento. Ao determinar prioridades e o foco de ação para cada um dos públicos, se torna menos difícil alocar melhor os recursos e encontrar formas de concentrar os esforços. Assim, a definição de "formas de utilizar melhor os pontos fortes, eliminar ou adequar os pontos fracos, usufruir das oportunidades externas e evitar as ameaças" (OLIVEIRA, 1999, p. 60) também se aplica diretamente aos empreendimentos de pequeno porte, como demonstra o quadro 6 .

\section{Quadro 6. Diagnóstico elaborado para profissional de arquitetura}

\begin{tabular}{|c|c|}
\hline Pontos fortes & Pontos fracos \\
\hline $\begin{array}{l}\text { - Proximidade e intimidade com o cliente. } \\
\text { - Facilidade de criação e compreensão } \\
\text { das demandas do cliente. } \\
\text { - Profissionalismo e ambição. } \\
\text { - Experiência extensa e diversificada. } \\
\text { - Boa relação com parceiros. } \\
\text { - Boa relação com a imprensa. } \\
\text { - Imagem de "bom preço". }\end{array}$ & $\begin{array}{l}\text { - Falta de organização. } \\
\text { - Ausência de sistema de cobrança formal. } \\
\text { - Centralização das decisões e ações. } \\
\text { - Dificuldade em focar a atuação. } \\
\text { - Excesso de diversificação. }\end{array}$ \\
\hline Oportunidades & Ameaças \\
\hline $\begin{array}{l}\text { - Aumento da procura em classe média-baixa. } \\
\text { - Valorização da criatividade e bom gosto. } \\
\text { - Momento de mudança e amadurecimento. } \\
\text { - Abertura para segmentação de mercado. }\end{array}$ & $\begin{array}{l}\text { - Mercado retraído e pouco estruturado. } \\
\text { - Dificuldade de gerar fidelização. } \\
\text { - Rotina intensa - pouco tempo para dedicação. } \\
\text { - Ação de decoradores. } \\
\text { - Imagem de custo elevado de projetos } \\
\text { de arquitetura. }\end{array}$ \\
\hline
\end{tabular}

Fonte: Barbosa (2006, p. 100) 
No exemplo que aqui tomamos, o planejamento de Relações Públicas deverá ser implantado no prazo de um ano, atendendo aos seguintes objetivos:

- Segmentar atuação para crescer no mercado;

- Diferenciar projetos de arquitetura e criar valor agregado ao atendimento;

- Gerar condições para focar atuação, organizando atividades administrativas;

- Posicionar profissional como arquiteta e decoradora experiente, que alia criação e bom gosto a um atendimento exclusivo;

- Separar a ação profissional da parte administrativa/ financeira;

- Atrair novos clientes, estimular indicações e fidelização investindo em visibilidade;

- Priorizar e hierarquizar relacionamentos com diversos públicos.

Para atingir esses objetivos, propomos as seguintes estratégias, que estão alinhadas com os três programas a serem apresentados a seguir, especificamente voltados para atingir três dos principais públicos de relacionamento: clientes, fornecedores e imprensa.

- Intensificação dos canais de comunicação informais existentes e criação de novos instrumentos formais, adequando-os ao perfil dos públicos de relacionamento;

- Foco da atuação em decoração planejada de ambientes, buscando sempre clientes e projetos que aliem arquitetura e decoração, como escritórios e salas comerciais de profissionais estabilizados (promotores, advogados, arquitetos, publicitários), clínicas de saúde (médicos, dentistas, esteticistas), quartos de criança, apartamentos de recém-casados, de homens solteiros etc.;

- Valorização dos públicos de relacionamento, principalmente fornecedores;

- Treinamento e orientação de fornecedores, preparando-os para uma nova estrutura de atendimento.

Os programas e projetos abaixo exemplificados foram pensados para ser implantados seguindo uma ordem de prioridade, definida a partir da hierarquização dos públicos apresentada anteriormente e do contexto de trabalho do profissional. O cronograma e a estimativa de custos de cada programa são partes muito particulares, por isso foram apresentados separadamente para oferecer ao profissional flexibilidade de escolha na implantação.

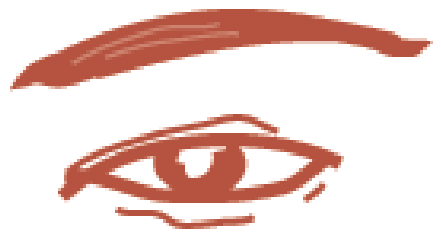




\section{Quadro 7. Detalhamento do "Programa Hi-tech"}

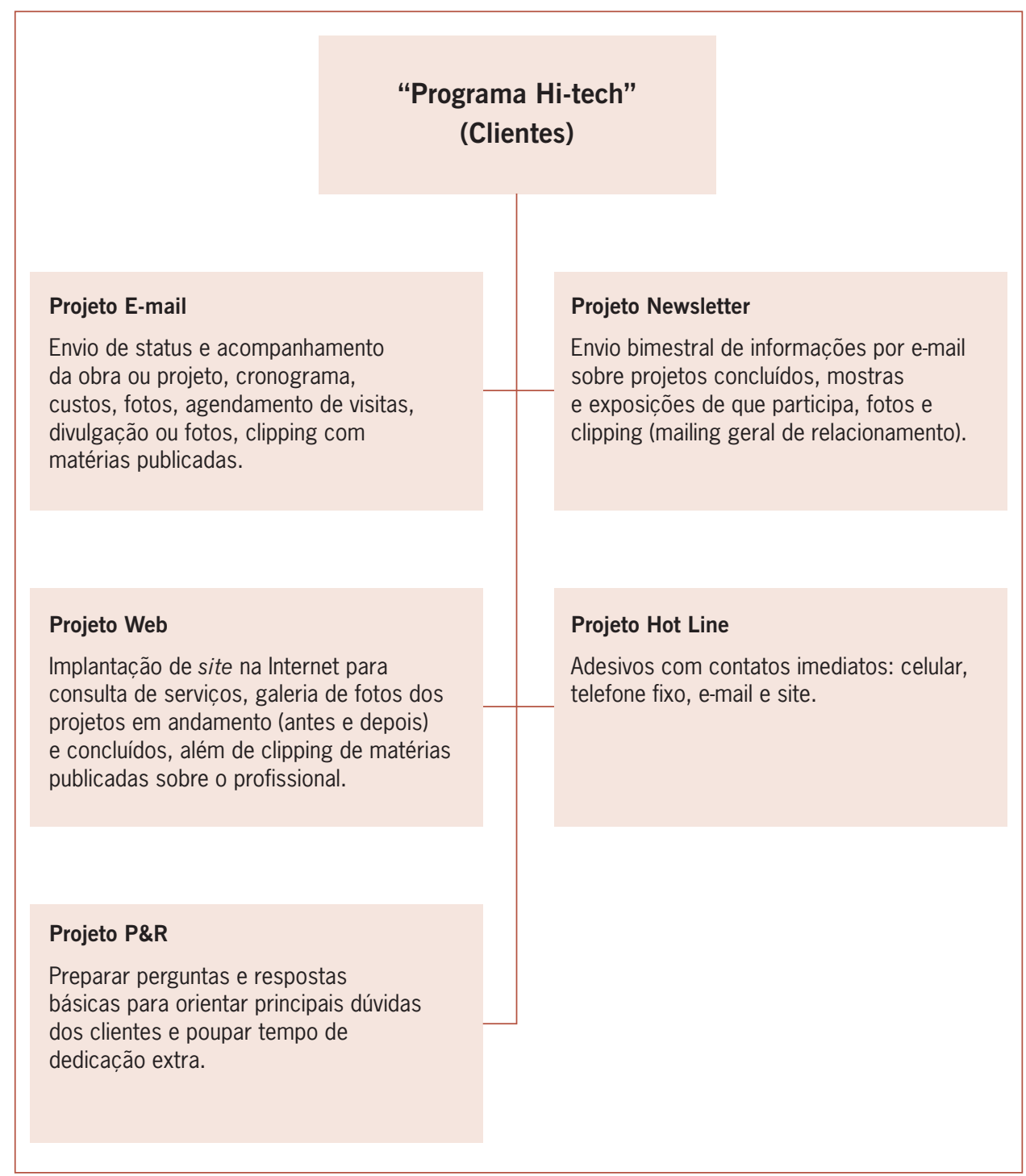

Fonte: Barbosa (2006, p. 104). 


\section{Quadro 8. Detalhamento do "Programa Educação"}

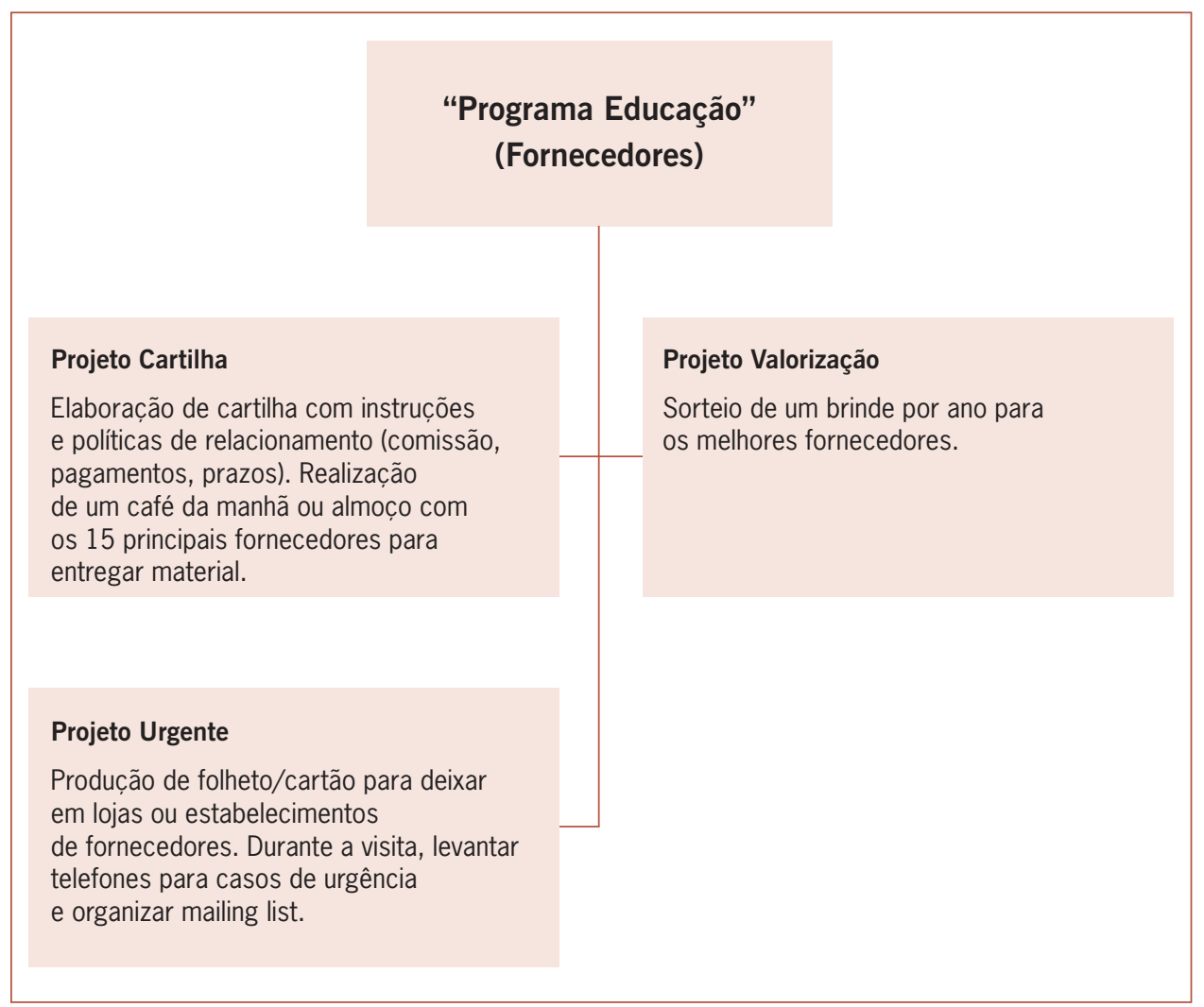

Fonte: Barbosa (2006, p. 106). 


\section{Quadro 9. Detalhamento do "Programa No Ar"}

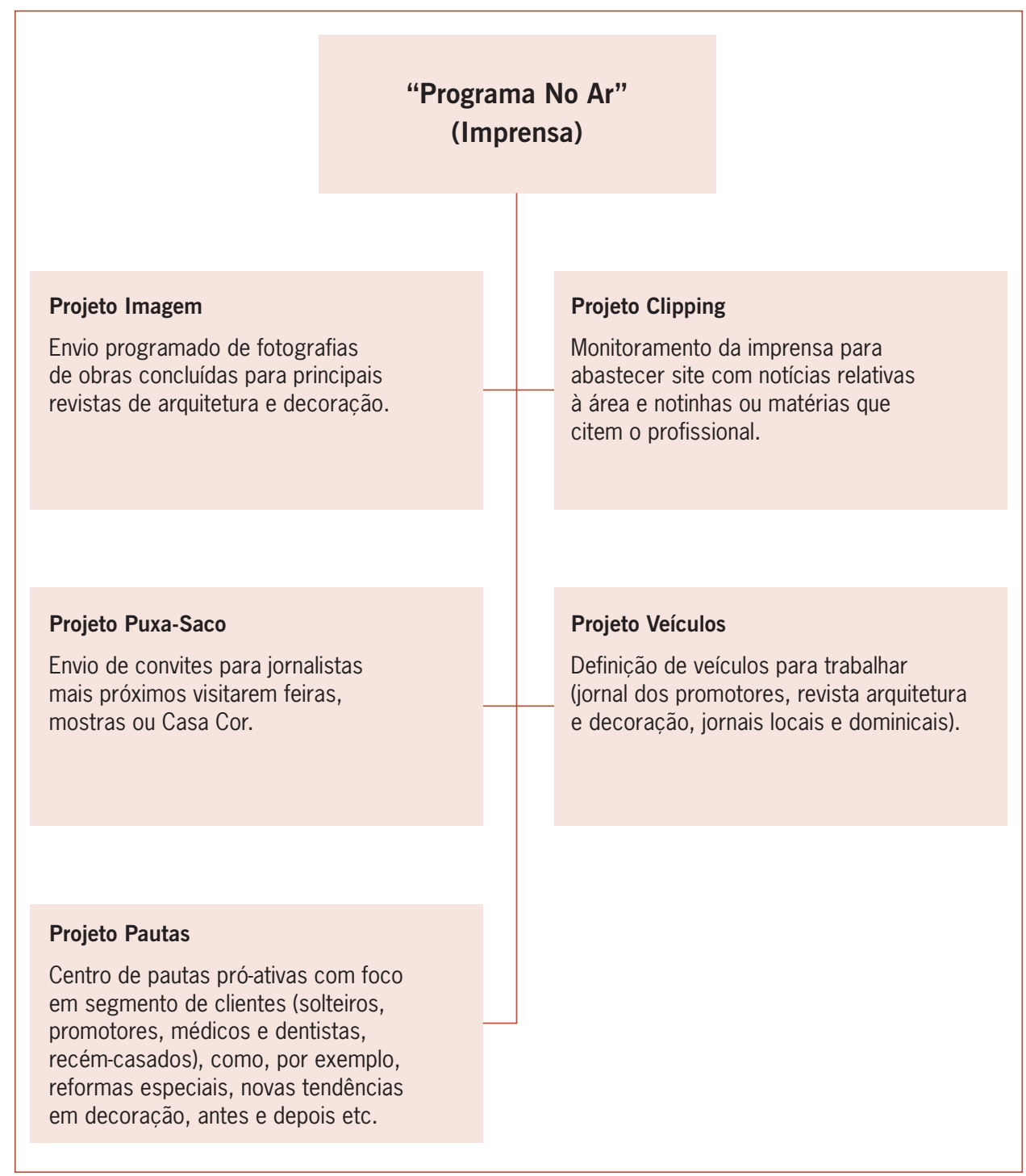

Fonte: Barbosa (2006, p. 110) 
Para avaliar os resultados desses programas, sugerimos os seguintes instrumentos e técnicas de controle:

\section{Quadro 10. Avaliação de resultados para profissional de arquitetura}

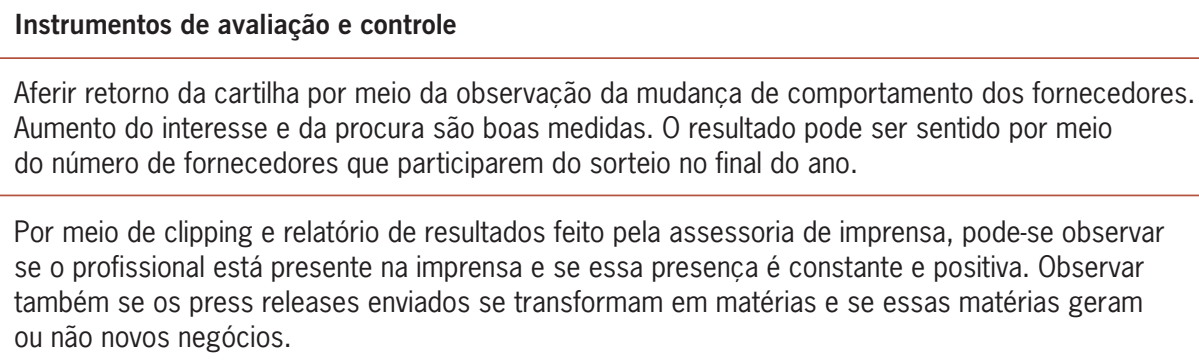

Aferir retorno da cartilha por meio da observação da mudança de comportamento dos fornecedores. Aumento do interesse e da procura são boas medidas. 0 resultado pode ser sentido por meio do número de fornecedores que participarem do sorteio no final do ano.

Por meio de clipping e relatório de resultados feito pela assessoria de imprensa, pode-se observar se o profissional está presente na imprensa e se essa presença é constante e positiva. Observar também se os press releases enviados se transformam em matérias e se essas matérias geram ou não novos negócios.

Medir o número de retornos por e-mail das mensagens e newsletters enviadas, o número de acessos ao site, o número de ligações de clientes para o hot line e a eventual redução de perguntas ou consultas desnecessárias, solucionadas pelo P\&R.

Aferir pelo controle do número de pop cards distribuídos, do tempo que levam para acabar nos pontos de veiculação, ou mesmo por meio do retorno dos clientes. Checar presença de clientes convidados na Casa Cor.

Fonte: Barbosa (2006, p. 114).

Como podemos perceber por meio desse exemplo de aplicação de planejamento, existem grandes desafios para as Relações Públicas voltadas a micro e pequenas empresas. Um deles é conhecer as peculiaridades de cada atividade, das muitas que podem ser trabalhadas. Na prática, cada organização possui um perfil e um foco totalmente diferente do outro e nem sempre os valores praticados para os serviços oferecidos a grandes organizações valem, na mesma medida, para os pequenos empreendedores. O plano aqui proposto, conforme demonstrado, pede um diagnóstico apurado, buscando-se informações específicas de cada profissional, para transpor esses desafios. São exemplos que podem ser aplicados para micro e pequenas empresas em diversos segmentos de atuação. A expansão e a aplicação dessas ferramentas e desses conceitos se mostram livres e ilimitadas. 


\section{Bibliografia}

ALBRECHT, Karl. Serviço ao cliente: a reinvenção da gestão do atendimento ao cliente. Trad. Afonso Celso da Cunha. Rio de Janeiro: Campus, 2002.

ALMEIDA, Martinho Isnard Ribeiro de. Desenvolvimento de um modelo de planejamento estratégico para grupos de pequenas empresas. 118 f. Tese (Doutorado em Administração) - Faculdade de Economia, Administração e Contabilidade. São Paulo: Universidade de São Paulo,1994.

BARBOSA, Carolina de Avellar. Planejamento de relações públicas aplicado para profissionais que trabalham por conta própria e para profissionais liberais. 161 f. Monografia (Especialização em Relações Públicas) Escola de Comunicações e Artes. São Paulo: Universidade de São Paulo, 2006.

CAETANO, Valderez; SANTANA, Nanci. Pequenas e médias puxam a indústria. Gazeta Mercantil, São Paulo, 01 fev. 2007. Capa e p. A-5.

CAVALCANTI, Marly. Diagnóstico organizacional. São Paulo: Loyola, 1981.

FERRARI, Maria Aparecida. Relações públicas: função estratégica e responsabilidade social. Estudos de Jornalismo e Relações Públicas, São Bernardo do Campo, Fajorp-Metodista, a. 1, n. 1, jun. 2003.

FRANC̣A, Fábio. Relações Públicas: visão 2000. In: KUNSCH, Margarida M. Krohling (org.). Obtendo resultados com relações públicas. São Paulo: Pioneira, 1997.

. Conceituação lógica de públicos em relações públicas. Estudos de Jornalismo e Relações Públicas, São Bernardo do Campo, Fajorp-Metodista, a. 1, n. 1, jun. 2003.

. Públicos: como identificá-los em uma nova visão estratégica. São Caetano do Sul, SP: Yendis Editora, 2004.

KON, Anita. Perfil dos trabalhadores por conta própria no Brasil. São Paulo: Escola de Administração de Empresas de São Paulo - Fundação Getúlio Vargas. Série de Relatórios de Pesquisa. Relatório número 31. NPP-DEG, 2001.

KUNSCH, Margarida M. Krohling. Planejamento de relações públicas na comunicação integrada. 4. ed. rev. e ampl. São Paulo: Summus, 2003.

MINTZBERG, Henry. The nature of managerial work. New York: Harper \& Row, 1973.

NASSIF, Luis. O cenário das microempresas. São Paulo, 2006. Disponível em: <http://luisnassifeconomia.blig.ig.com.br>. Acesso em: 13 dez. 2006.

OLIVEIRA, Djalma de Pinho Rebouças de. Planejamento estratégico: conceitos, metodologias e práticas. 14. ed. São Paulo: Atlas, 1999.

PINHEIRO, Maurício. Gestão e desempenho das empresas de pequeno porte: uma abordagem conceitual e empírica. 269 f. Tese (Doutorado em Administração) - Faculdade de Economia, Administração e Contabilidade. São Paulo: Universidade de São Paulo, 1996.

SEBRAE-SP. Observatório das micro e pequenas empresas. São Paulo, nov. 2006. Disponível em: <http://www. sebraesp.com.br/Principal/Conhecendo\%20a\%20MPE/>. Acesso em: 25 fev. 2007. 
RELAÇÕES PÚBLICAS SOMENTE PARA GRANDES EMPRESAS? - CAROLINA DE AVELLAR BARBOSA

TACHIZAWA, Takeshy; REZENDE, Wilson. Estratégia empresarial: tendências e desafios. Um enfoque na realidade brasileira. São Paulo: Makron Books, 2000.

TAVARES, Mauro Calixta. Planejamento estratégico: a opção entre sucesso e fracasso empresarial. São Paulo: Harbra Business, 1991.

VIEIRA, Eduardo; CLEMENTE, Isabel. A vida sem emprego. Época, Rio de Janeiro, maio 2006. Matéria de capa. Disponível em: <http://revistaepoca. globo.com/Revista/Epoca/0,,EDG74047-5990-416,00.html>. Acesso em: 29 jul. 2006.

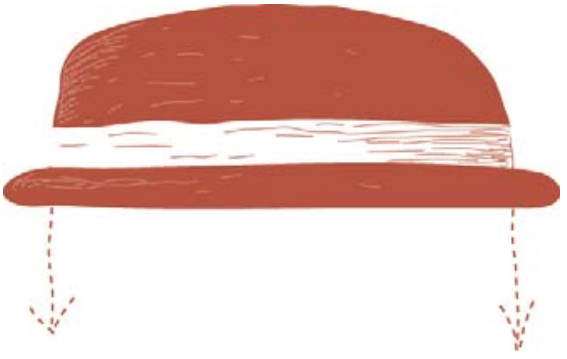

ANO 3 • NÚMERO $5 \cdot 2^{\circ}$ SEMESTRE DE 2006 • organicom • 151 